Original Article

\title{
COMPARISON OF ANTIBACTERIAL ACTIVITY OF GARLIC AGAINST AEROBIC AND ANAEROBIC BACTERIA
}

\author{
K. G. DHANUSH ${ }^{1 *}$, S. S. M. UMAMAGESWARI ${ }^{2}$, M. MALAVIKA ${ }^{3}$, G. BHUVANESHWARI ${ }^{4}$ \\ ${ }^{1}$ Saveetha Medical College and Hospital, Kuthambakam, Chennai 600124, Tamilnadu, 2,3,4Department of Microbiology, Saveetha Medical \\ College and Hospital, Kuthambakam, Chennai 600124, Tamilnadu \\ Email: dhanushgopu13@gmail.com \\ Received: 15 Sep 2020, Revised and Accepted: 17 Nov 2020
}

\section{ABSTRACT}

Objective: To compare the antibacterial activity of garlic against aerobic and anaerobic bacteria.

Methods: Antimicrobial activity of garlic is performed by Agar cup diffusion technique for 3 bacteria Staphylococcus aureus, E. coli and clostridium perfringens.

Results: By performing the technique with proper guidance, it is observed that the Staphylococcus aureus specimen shows sensitivity to garlic whereas the other two specimens Escherichia coli and clostridium perfringens doesn't show any sensitivity to garlic.

Conclusion: Due to its vast antibacterial activity of garlic, it can be used along with other antibiotics to increase its efficiency.

Keywords: Antibacterial activity, Garlic, Staphylococcus aureus, Escherichia coli, Clostridium perfringens and Agar cup diffusion technique

(C) 2021 The Authors. Published by Innovare Academic Sciences Pvt Ltd. This is an open access article under the CC BY license (https://creativecommons.org/licenses/by/4.0/) DOI: https://dx.doi.org/10.22159/ijcpr.2021v13i1.40811. Journal homepage: https://innovareacademics.in/journals/index.php/ijcpr

\section{INTRODUCTION}

Garlic (Allium sativum) is a species in the onion genus, Allium it has a history of several thousand years of human consumption and use. It's wide range of medicinal efficiency is still under research by many wellknown researchers [1]. The therapeutic usage of garlic was also noticed in some areas due to its activity against gram positive and gram negative bacteria. The aim of this investigation is to compare the antibacterial activity of garlic against the aerobic bacteria and anaerobic bacteria. For this investigation aerobic bacteria Staphylococcus aureus ATCC 25923, Escherichia coli ATCC 25922 and an strict anaerobe Clostridium perfringens ATCC 3624 are used.

Aerobic bacteria are those which require oxygenated environment for their growth and development. Absence of oxygen may have adverse effect on the organism.

Staphylococcus aureus is an aerobic gram positive cocci, present in normal human Flora, upper respiratory tract and on the skin. Some strains may cause skin infection and the spread is by relation with infected person.

Escherichia coli is the most common aerobe found in the normal intestinal Flora and keeps it healthy. It is an gram negative bacilli. Only some strains of E. coli are infective and causes diarrhea. But, detection of E. coli, especially thermotolerant $E$. coli is taken as an indicator of contamination of drinking water with human or animal feces.

Anaerobic bacteria lacks cytochrome system for oxygen metabolism and cannot neutralize toxic oxygen metabolites. Hence they grow in the absence of oxygen. They may react negatively or even die in the oxygenated environment. They need special requirements for their growth in culture mediums.

Clostridium perfringens is an strict anaerobe and spread by food and water contamination. Clostridium perfringens on extreme may cause gas gangrene. It is also caused by group A Staphylococcus aureus species.

The relation between these three bacteria is that they all cause food poisoning. This investigation is about to tell us about the activity of garlic against all these bacteria.

\section{MATERIALS AND METHODS}

\section{Extract}

Garlic (Allium sativum) should be collected in a fresh manner under proper guidance and stored it for the process.

\section{Microorganisms}

The bacterial test organisms Staphylococcus aureus ATCC 25923, Escherichia coli ATCC 25922 and Clostridium perfringens ATCC 3624 are obtained from the microbiology department.

\section{Antimicrobial susceptibility testing}

Agar cup diffusion technique

Also called as Kirby-Bauer method is an antibiotic susceptibility testing method. It is used to find the susceptibility of a bacterium to an antibiotic. Mueller-Hinton Agar is usually used and gives satisfactory growth for a wide range of organisms [2].

\section{Principle}

The antibiotic impregnated disk when placed over an already inoculated agar medium with the test bacterium would pick up moisture and the antibiotic would diffuse radially outward on the medium. It produces a gradient of high concentration of antibiotic at the edges of the disk and slowly the concentration decreases as it diffuses radially outward. Thus creating a zone of inhibition around the disk, where the bacterium could not grow, if the antibiotic is effective against the test bacterium [2].

\section{Methodology}

Preparation

Take 2 NA plates 1 and 2. Dry the plates. Take Staphylococcus aureus and $E$. coli specimens inoculate them in peptone water in separate test tubes and incubate them for 20 min under $37^{\circ}$ Celsius. After incubation, take these two organisms and undergo lawn culture in the two NA plates separately. i.e. Staphylococcus aureus in NA plate 1 and E. coli in NA plate 2. Take the Clostridium perfringens specimen and perform lawn culture directly in blood plate. 


\section{Introduction of garlic}

Take 3 Capillary tubes and cut a well on the 3 culture plates respectively. Add 10 microgram of garlic in each culture plate and incubate them for $24 \mathrm{~h}$ under $37^{\circ}$ Celsius. Assessment is based on the ability of bacteria to show sensitivity to garlic.

\section{RESULTS}

After performing the technique, observation is made after $24 \mathrm{~h}$. The gram positive cocci Staphylococcus aureus shows sensitivity to garlic. It is an aerobe (fig. 1) the gram negative bacilli Escherichia coli doesn't show any sensitivity to garlic. It is an aerobe (fig. 2). The gram positive bacilli Clostridium perfringens doesn't show any sensitivity to garlic. It is an strict anaerobe (fig. 3).

The pictures of the 3 culture plates prepared by agar cup diffusion technique has been pinned below.

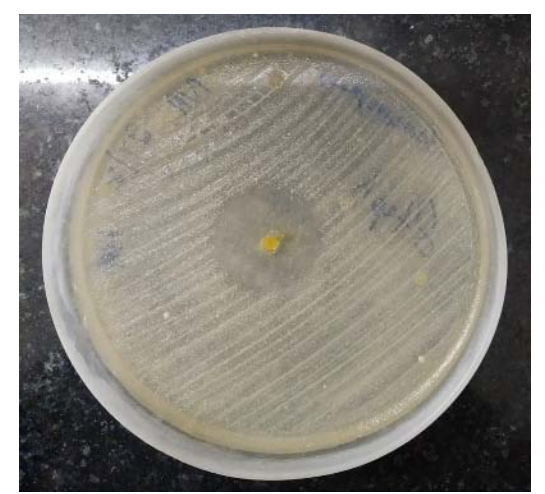

Fig. 1: Staphylococcus aureus

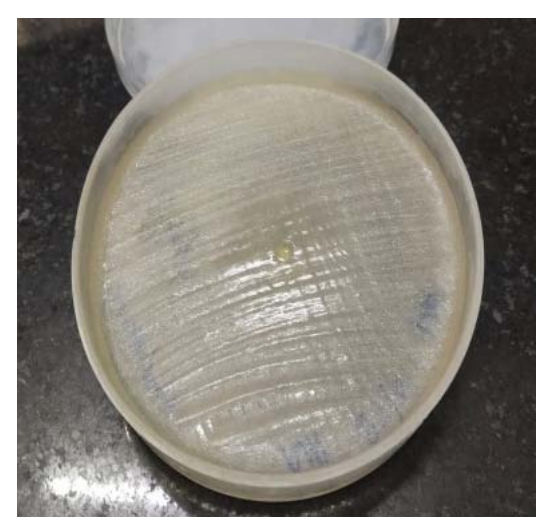

Fig. 2: Escherichia coli

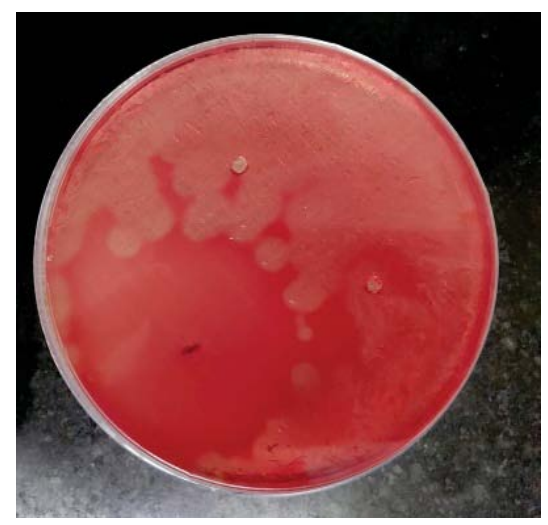

Fig. 3: Clostridium perfringens

\section{DISCUSSION}

Garlic has many medical properties and it is well documented by Egyptian, Greek and Chinese civilization. Scientist found that it contains more sulfur compounds. It is low in calories and rich in vitamin C, B6 and Manganese. It help to prevent and reduce the severity of common illness like the flu and common cold to control blood pressure reduce LDL, Cholesterol levels and reduce the risk of heart attack [3].

Aerobic bacteria are those which cannot survive in the absence of oxygen and even may die. They need the presence of oxygenated environment for its growth and development. Whereas anaerobic bacteria doesn't require oxygen for its growth and development. Strict anaerobes may even die in the presence of oxygen. Facultative anaerobes are those which can survive in presence of oxygen as well as in the absence of oxygen. It is all based on the energy production of on organism for its survival. In the oxygenated environment, aerobes and facultative anaerobes produce ATP by aerobic respiration. In the absence of oxygen, anaerobes and facultative anaerobes produce energy by fermentation. In this experiment, the garlic extract has been used against three important bacterial species and its activity is noted for its usage against it [4-7].

Staphylococcus aureus is an aerobic and an gram positive cocci. It contains various virulence factors such as cell wall associated factors (peptidoglycan, teichoic acid, cell surface adhesions, protein $A$ ), toxins (hemolysins- $\alpha, \beta, \gamma, \delta$, leukocidins, exfoliate toxin, enterotoxin, toxic shock syndrome toxin) and extracellular enzymes (coagulase, heat stable thermonuclear, deoxyribonuclease, fibrinolysin). It causes a spectrum of infections such as skin and soft tissue infections (folliculitis, furuncle, carbuncle, impetigo, etc.), Musculoskeletal infections (pyomyositis, abscess, septic arthritis, osteomyelitis), respiratory tract infections (septic pulmonary emboli, empyema, pneumothorax, post viral pneumonia), bacteremia, UTI, toxin mediated illnesses (food poisoning, toxic shock syndrome), etc. Penicillin $\mathrm{G}$ and vancomycin is used for their treatment. Also from this experiment it is found to be sensitive to garlic extract. Hence can be used along to increase the efficiency of antibiotics [8].

Escherichia coli is an aerobic bacteria and an gram negative bacilli. It is an most important human pathogen to be found in the gut of humans. The virulence factors of E. coli includes it's surface antigens ( $\mathrm{O}$ antigen, $\mathrm{H}$ antigen, capsular antigen, fimbrial antigen), toxins (enterotoxins, hemolysins, cytotoxic necrotizing factor 1) and siderophores. It causes UTI, diarrhea, pneumonia, meningitis, bacterial prostitis, osteomyelitis, abdominal infections (peritonitis, visceral abscess) and endovascular infection. Treatment is based on the antimicrobial susceptibility test report. In this experiment, the $E$. coli doesn't show any sensitivity to garlic extract used. Hence, honey cannot be used for its treatment $[9,10]$.

Clostridium perfringens is an strict anaerobe and an grams positive bacilli. These are the commensals of large intestine of humans and animals. The virulence factors produced are grouped under major toxins $(\alpha, \beta, \varepsilon, l)$, minor toxins $(\gamma, \delta, \lambda, \kappa, \theta, \eta, \mu, v)$, enterotoxin and soluble substances (neuraminidase, histamine, bursting factor, circulating factor). They cause a series of infections includes wound infection (simple infection, anaerobic cellulitis, gas gangrene), food poisoning, enteritis necroticans, necrotizing enterocolitis, gangrenous appendicitis, bacteremia, meningitis and brain abscess. Treatment for gas gangrene caused by clostridium includes the combination of drugs penicillin and clindamycin. But early surgical debridement is the most crucial step in the management of gas gangrene. In this experiment, garlic extract has been tested against clostridium perfringens, but the organism doesn't show any sensitivity to the extract. Hence, garlic cannot be used for its treatment $[11,12]$.

\section{CONCLUSION}

The garlic exhibits the antibacterial activity for staphylococcus aureus but not against $E$. coli and clostridium perfringens. It's medicinal value is still to be discussed at various levels. Several findings of other researchers show its efficiency and resistance towards several other bacteria. Hence, it is important to note it's 
antibacterial activity even it is not an antibiotic agent. It is also used along with antibiotics which increases the activity of antibiotics.

This investigation deals only with limited number of organisms due to provided situation, the further antibacterial activity of garlic and it's resistance to different organisms will be dealt in future studies.

\section{ACKNOWLEDGEMENT}

Highly thankful to the mentors, the HOD of the microbiology department, the Dean and the management of the Saveetha Medical College and Hospital, Chennai, for the opportunity and the laboratory facility.

\section{FUNDING}

Nil

\section{AUTHORS CONTRIBUTIONS}

All the authors have contributed equally.

\section{CONFLICT OF INTERESTS}

Declared none

\section{REFERENCES}

1. Kyu Hang Kyung, Kyung Suk Park, Youn Soon Kim. "BeIsolation and characterization of bacteria resistant to the antimicrobial activity of garlic" J Food Sci 1996;61:226-9.

2. Tendency, Eleonor A. Disk diffusion method. SEAFDEC, Aquaculture Department Japan, Chapter 2; 2004. p. 14-29.
3. FC Groppo, JC Ramacciato, RHL Motta, PM Ferraresi. A sartoratto activity of garlic against oral streptococci. Int J Dental Hygiene 2007;5:109-15.

4. E Noori S Al-Waili, Khelod Y Saloom, M Akmal, Thia N Al-Waili, Ali N Al-Waili, Hamza Al-Waili, et al. Heating, storage, and ultraviolet exposure on antimicrobial activity of garlic juice. J Med Food 2007;10:208-12.

5. Obi CL, Mazarura E. Aerobic bacteria isolated from blood cultures of patients and their antibiotic susceptibilities in Harare, Zimbabwe. Cent Afr J Med 1996;42(Suppl 12):332-6.

6. Brook I. Enhancement of growth of aerobic and facultative bacteria in mixed infections with Bacteroides species. Infect Immun 1985;50:929-31.

7. Gorbach SL, JG Bartlett. Anaerobic infections. N Engl J Med 1974;290:1177-84, 1237-45, 1289-94.

8. Tong SY, Davis JS, Eichenberger E, Holland TL, Fowler VG Jr. Staphylococcus aureus infections: epidemiology, pathophysiology, clinical manifestations, and management. Clin Microbiol Rev 2015;28:603-61.

9. Alexander TJL, Gyles CL. Escherichia coli in domestic animals and humans. Wallingford, United Kingdom: CAB International; 1994. p. 151-70.

10. James P Nataro, James B Kaper. Diarrheagenic escherichia coli. Clin Microbiol Rev 1998;11:142-201.

11. Kiu R, Hall LJ. An update on the human and animal enteric pathogen clostridium perfringens. Emerg Microbes Infect 2018;7:141.

12. Stevens DL, Aldape MJ, Bryant AE. Life-threatening clostridial infections. Anaerobe 2012;18:254-9. 